\title{
A CRITICAL EVALUATION OF THE PROPOSED TREATMENT OF SPECIAL COST ADVANTAGES IN EXCESSIVE PRICES LAW
}

\author{
Andrew Sylvester \\ University of Johannesburg \\ andrewsylv@gmail.com
}

Received: June 2014

Accepted: September 2014

\begin{abstract}
Firms have a special cost advantage when they receive a discount or subsidy without assuming any risk or without being innovative. It is thus a received benefit, rather than an earned benefit, which results in a cost below the normal competitive level. The treatment of these special cost advantages has been a complicating factor when the firm in question is a dominant firm accused of charging an excessive price. The relevant benchmark against which to assess the price charged by the firm is the notional competitive market price, which in turn is linked to the cost of production under competitive conditions. This led to the Competition Appeal Court recommending that special cost advantages should be excluded from the cost build-up of the dominant firm when assessing excessive prices allegations. This would artificially inflate the dominant firm's costs and reduce the likelihood of a finding against the firm. This recommendation by the CAC has a number of theoretical and practical problems, and it remains unclear how special cost advantages should be treated in South African competition law cases.
\end{abstract}

Keywords

Excessive prices, special cost advantages, competition law, abuse of dominance, monopoly, exploitative abuse

Mr A Sylvester is Research Fellow, Centre for Competition, Regulation and Economic Development, University of Johannesburg; DNA Economics. 


\section{INTRODUCTION}

A special cost advantage is a specific type of cost advantage which is not earned by the firm but rather received from an external stakeholder. It is thus neither a reward for assuming risk nor a return for past innovation. A common source of special cost advantages are state interventions in strategic markets which the state is trying to develop. Irrespective of the source of the special cost advantage, the result is a cost structure which is below that which would result under normal competitive conditions. Where the market is sufficiently competitive, this would result in lower prices to the benefit of downstream firms or consumers. However, where the market is not competitive, a portion of these special cost advantages will be transformed into additional profits.

The issue of special cost advantages has particular relevance in the assessment of excessive prices cases in competition law. This is because these cases require the assessment of the competitive counterfactual price, and hence the level of costs under competitive conditions. Critical to this evaluation then, as it was in the excessive prices case against ArcelorMittal South Africa (AMSA), is how to construct the notional costs which would have existed under competitive conditions.

AMSA was previously the South African state-owned iron and steel company which both extracted iron ore and produced steel. The two functions were split in 2001 and the steel production company was privatised in 2003 (AMSA, 2013). AMSA, the new owners of the steel production assets, retained a deal to purchase iron ore from its former sister company at a steep discount, and also negotiated tax incentives with the Department of Trade and Industry.

In 2002 Harmony Gold and Durban Roodepoort Deep complained to the Competition Commission of excessive prices for flat steel in South Africa. The case was heard only in 2006 after the complainants took their case independently to the Competition Tribunal. One of the issues raised in the case was that AMSA received special cost advantages and, in return, the Department of Trade and Industry expected there to be developmental pricing, which never transpired (Competition Tribunal, 2007). While this was not important to the Tribunal's decision to uphold the complaint and levy an administrative penalty of R692m against AMSA, the Competition Appeal Court (CAC) did make a suggestion on this issue when deciding AMSA's appeal of the Tribunal's decision (CAC, 2009).

The argument used by the CAC is that the economic value against which a firm's price should be compared, if the cost build-up method is used, should not be the costs of the monopolist. Rather, it should be the costs of a notional competitive firm. If the monopolist enjoys a special cost advantage, it follows that the cost a competitor firm would pay should replace the especially low cost when conducting the cost build-up. Section 2 delves deeper into the CAC's arguments, and section 3 examines how to follow the CAC's suggestion to 'disregard' the special cost advantage. Sections 4 and 5 describe complications in the analysis firstly with regard to measurement issues and then with regard to the difference between a special cost advantage and a cost advantage. Lastly, section 6 concludes.

\section{SUGGESTED TREATMENT FOR SPECIAL COST ADVANTAGES}

As one of its reasons for the decision to set aside the decision of the Tribunal in the Harmony Mittal excessive prices case, the CAC (2009) gave various suggestions on how to approach 
excessive prices cases. In particular, the CAC identified various methodologies of estimating economic value. The economic value of a product is essential to an excessive prices investigation, because is the benchmark against which actual prices are compared in deciding if the difference is excessive or not.

The CAC interpreted the term economic value as the price that would have prevailed in the long run under competitive conditions (CAC 2009: para 40). The CAC gives further clarity by stating that the market does not necessarily have to be perfectly competitive in the short run; however, in the long run all supracompetitive returns are eliminated. This is a very rigid interpretation by the $C A C$, because in holding that economic value is equal to the long-run perfectly competitive price, it also follows that economic value is the economic cost at minimum efficient scale. A monopolist is not held to pricing at this level, however, but is required to price at a level which bears a reasonable relation to this level.

Interestingly, none of the suggested tests by the CAC reflect this rigid definition of economic value. Price cost tests and profitability analysis are most closely related to this definition of economic value; however, they don't fully adjust the market structure from monopoly to perfect competition. Two attempts are made to move closer to perfectly competitive cost levels: (i) eliminating inefficiencies from the monopoly costs and (ii) adjusting costs where the firm enjoys special cost advantages. It is with the terms of the suggested treatment for this second adjustment that this paper is mainly concerned.

Other tests suggested by the CAC and discussed in the literature on excessive prices (see Motta \& De Streel, 2007) include comparing the price charged by the dominant firm between different markets, over time in the same market, or to different customers in the same market. These tests don't make any attempt to construct a perfectly competitive counterfactual but instead are short-cuts to understanding what economic value might be, or at least an upper limit of economic value.

When performing the price cost tests and profitability analysis the firm's accounting costs need to be transformed into economic costs. A pertinent issue here, as previously mentioned, is whether and how to adjust costs for cost items where the firm has received a special cost advantage. This is different from a competitive advantage gained from innovation or fortune and which might result in a cost advantage. Rather, a special cost advantage is one which the firm received from the outside, such as an incentive from the state. The CAC explains how these special cost advantages should be addressed:

[I]n determining the economic value of a good or service, the cost savings to the firm resulting from the subsidised loan or the lower than market rental - or indeed any other special advantage, current or historical, that serves to reduce the particular firm's costs below the notional competitive norm ought to be disregarded. (CAC, 2009: para 43)

This suggestion is made because the Act identifies that what needs to be excessive for a finding of excessive pricing is not the difference between the price charged by the firm and the cost of producing that product, but rather the price charged and the economic value of that product. If the firm were to acquire inputs at a price which is lower than the economic value of those inputs, it does not reduce the economic value of the dominant firm's output.

It seems that the CAC arrived at this conclusion on the advice of amici curiae, specifically the submissions of Robert Petersen SC, Hamilton Maenetje and Michelle le Roux (2008). The amici curiae link a definition for economic profit to the issue of economic value in explaining how input costs should be calculated. The definition used is from the Penguin Dictionary of 
Economics, which the amici curiae modify to: 'accounting profit and economic profit will be the same only where all factors of production have been credited with their full (one should add, competitive) opportunity costs' (Petersen et al, 2008: para 22).

Implicit in this definition above is that accounting costs and economic costs will differ where the opportunity cost is different to the accounting cost. Thus, where shareholders invest funds in a business which they could have invested for a positive return elsewhere, the opportunity cost of not investing the funds elsewhere needs to be included as an economic cost. This is the reason why a reasonable return on capital is included in economic profitability analysis (although the CAC explains that the term 'reasonable return' should not be used). By the same logic, the amici curiae continue, any special cost advantage for a certain input enjoyed by the firm should be valued at the opportunity cost rather than the actual amount paid. The amici curiae state it thus:

\footnotetext{
The cost savings to the firm resulting from the subsidised loan or the lower than market rental - or indeed any other special advantage, current or historical, that serves to reduce the particular firm's costs below the notional competitive norm - ought to be disregarded when determining the "economic value" of the goods or services which it supplies. (Petersen et al, 2008: para 23.1)
}

The first observation to make is that the CAC's conclusion on the issue (CAC, 2009: para 43) is an almost verbatim copy of this conclusion by the amici curiae. The only difference is that the amici curiae focused on the issue of opportunity cost extensively in their reasoning leading up to their conclusion, while the CAC makes no mention of opportunity cost, retaining only the term 'notional competitive norm'. This difference is not simply a point of semantics. Opportunity cost is a firm-specific measure which asks what the next best alternative to the firm would be if they did not use the input or factor for its primary purpose. The notional competitive norm suggests some market related price for the input which is independent of firm specific realities.

The example of a subsidised loan is used both by the amici curiae and by the CAC and illustrates well the difference between opportunity cost and notional competitive norm. To be fair to the $\mathrm{CAC}$, the amici curiae must also have applied the notional competitive norm concept rather than opportunity cost, which is peculiar given the lengths they go to in explaining that costs should be valued at opportunity cost. Here the idea is that the government offers a firm a subsidised loan in order to incentivise it to build a production facility. The firm benefits because it pays a lower interest rate on the debt than it would have had to had it raised the capital on the open market.

In the situation described above, using the notional competitive norm would suggest increasing the interest costs of the firm to what it would have paid had it had to borrow on the open market rather than receiving a subsidised loan from the government.

Using the opportunity cost concept instead would require an answer to the question of what else the firm could have done with the funds borrowed at the subsidised interest rate. Had the firm been able to borrow the money at the lower interest rate from the government and then lent it out on the open market at the prevailing interest rate, then the opportunity cost would indeed have been the prevailing interest rate, as was the case when applying the notional competitive norm concept. If, however, the government had lent the firm the funds on condition that it used them for a specific purpose, then the firm would not have had the option of then lending the money out on the open market. Indeed, the firm would only have had two options: borrow at the subsidised rate and spend it as per the condition; or, do not borrow the money at all. The opportunity cost is the value of the second best option, which, in this case, is to not borrow the funds at all. The value of not borrowing the funds is that the firm does not have to pay the 
agreed interest. Thus the opportunity cost where the preferential loan is conditional upon a specific use is the same as the actual or accounting cost: the agreed interest payable on that loan.

There may be a significant difference in results depending on which standard to adopt: the opportunity cost standard or the notional competitive norm standard. The amici curiae seem to erroneously conflate the two, while the CAC seems to focus on the notional competitive norm but does not explicitly state that the opportunity cost method is invalid. Indeed, given that the CAC bases its conclusions on those of the amici curiae, it may not have contemplated any difference between the two and thus not identified any conflict requiring clarification.

Not only is the CAC's conclusion confusing in terms of the standard it suggests should be applied, but it is also very broad in its coverage. It includes all characterisations of costs irrespective of when they advantaged the firm: both 'current and historical' (CAC 2009: para 43). This means that the model of the counterfactual cost would also need to take account of changed incentives when an investment decision is made. Had variable or fixed costs been different historically, plant sizes and the technology mix used by the firm might be different in the period under review. This raises a new dimension to trying to implement the CAC's suggestion.

\section{HOW TO DISREGARD SPECIAL COST ADVANTAGES}

Perhaps the first interpretation of the CAC's suggestion is simply to use the competitive market price in place of the actual price paid for the discounted cost item when calculating the cost build-up for the product. In this way the special cost would be 'undone', and the notional competitive cost could then be used when performing price cost and profitability tests.

This seems to be the logic followed by Langbridge and Mackenzie (2010) in their review of the CAC's decision. Here they understand the CAC to be suggesting that 'a market based value determination, rather than one based on the individual firm's cost structure' ought to be used when estimating economic value (Langbridge \& Mackenzie, 2010:5). Next they suggest that, where a firm does enjoy a special cost advantage, it would be appropriate simply to add the value of the cost advantage to the cost of the firm in order to arrive at a good approximation of economic value.

This interpretation is, however, correct only under strict assumptions. The problem with this simple interpretation arises because the cost of production is not altered to the competitive level. Maximising profits in a competitive industry is synonymous with minimising costs, because no economic profits can be earned in the long run. A monopolist's decision to maximise profits, however, is somewhat different and needn't coincide with cost minimisation. Simply adding the cost advantage to the monopolist's costs and claiming those to approximate the competitive cost either contradicts fundamental economic understanding of costs, or rests on extraordinary assumptions (for example: perfectly inelastic demand or constant average total costs).

Note that the above commentary is not concerning monopoly inefficiency but rather economies and diseconomies of scale. FIGURE 1 illustrates this point by showing that a monopolist need not produce at minimum efficient scale and that simply adding the value of the special cost advantage back onto the firm's actual costs does not produce any meaningful result. 


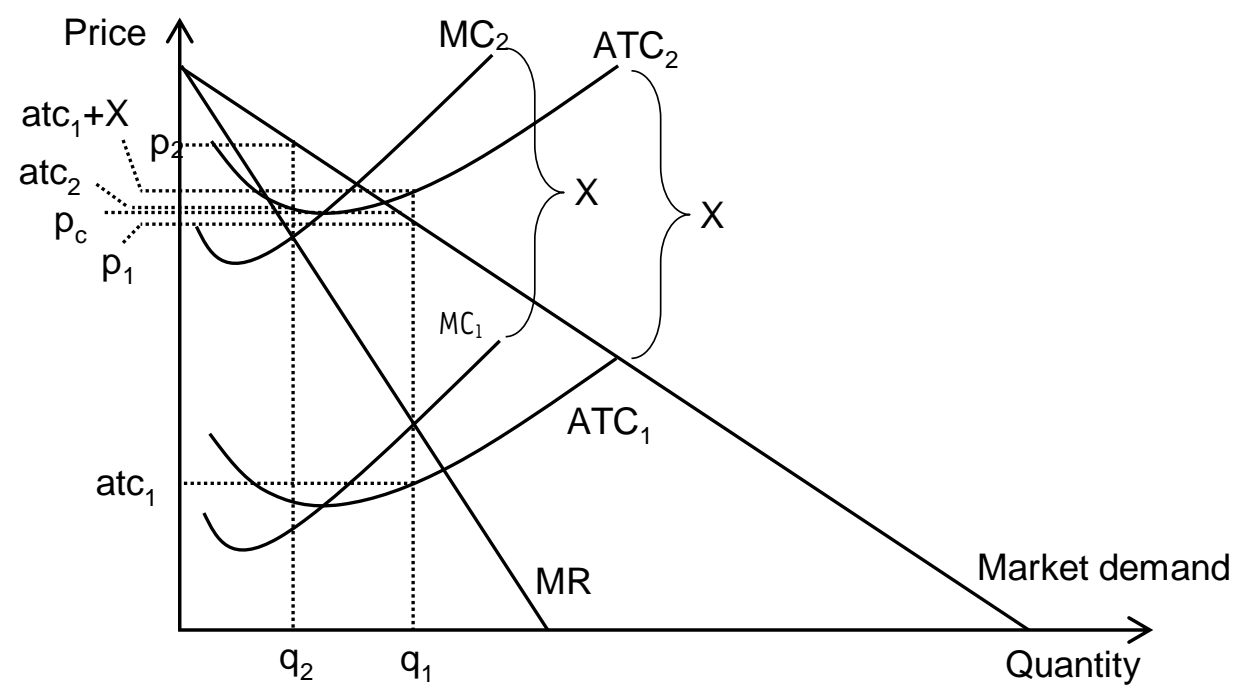

FIGURE 1: Unconstrained monopoly with a special variable cost advantage and increasing marginal costs

Source: Author's construction

This monopoly currently receives a special cost advantage on a variable cost equal to $X$ per unit. It has increasing marginal costs and would have average total costs ATC $_{1}$ with the special variable cost advantage of $X$ and $\mathrm{ATC}_{2}$ without the special variable cost advantage. To maximise profit when it has the special cost advantage it will produce $q_{1}$ output priced at $p_{1}$ and average total cost of atc $\mathrm{c}_{1}$. Using the approach that simply adds the cost discount received to the firms' average total costs would result in using $a \mathrm{C}_{1}+X$ as the proxy for the notional competitive norm. This value, in the extreme case presented in FIGURE l, is higher than:

- the price charged by the monopoly of $\mathrm{p}_{1}$;

- the average total cost of the monopoly had they never received the special cost advantage in the first instance of atc $_{2}$; and,

- the average total cost and price under competitive conditions of $p_{c}$.

The whole purpose of adding back $X$ is to estimate the notional competitive norm, or, to phrase it differently, to estimate costs produced if the market had a larger number of suppliers competing with one another for both customers and inputs. However, it is evident that the result not only overestimates the costs (and prices) that would result under a competitive market structure, but may also overestimate the costs were the monopolist not given the special cost advantage in the first instance. It is important to note that, while FIGURE $I$ is purposely depicted for a large value of $X$, the conclusions hold for smaller values of $X$ too.

The outcome that the average total cost plus the special cost advantage is greater than the cost were the monopoly to have paid the higher cost and arrived at a different output and pricing decision is an outcome of the shape of the cost curves. If marginal cost (and hence average total cost) is upward-sloping, as in FIGURE 1 , then the observed outcome will hold. If costs are downward-sloping, which would be the case in a natural monopoly where there are very large 
fixed costs, then the outcome would be reversed. However, what is constant is the fact that adding the special cost advantage does not produce the counterfactual cost level in either instance. Indeed, the only two cases where adding the cost advantage to the monopoly's costs does result in the competitive cost is where average total costs are constant or where demand is perfectly inelastic.

The fact that a monopoly operates off a different point on its cost curve to that of firms in a competitive market is only the first complication in evaluating the CAC's suggestion. The second complication arises if the special cost advantages alter investment decisions. To disregard historical cost advantages which changed the cost of investment one would need to determine a counterfactual plant size. Put differently, some special cost advantages change the shape of an industry, indeed sometimes even create an industry where there otherwise would not be any activity. For example, the special cost advantages in the form of import rebates offered to motor vehicle producers through the Motor Industry Development Programme (MIDP) has resulted in the creation of motor vehicle assembly facilities in South Africa where firms would otherwise not have been incentivised to build large facilities or perhaps any facilities at all.

This point is perhaps more clearly shown in FIGURE 2, where incentives have resulted in a 'dominant firm' with completely different cost structures to smaller firms in the 'competitive fringe'.

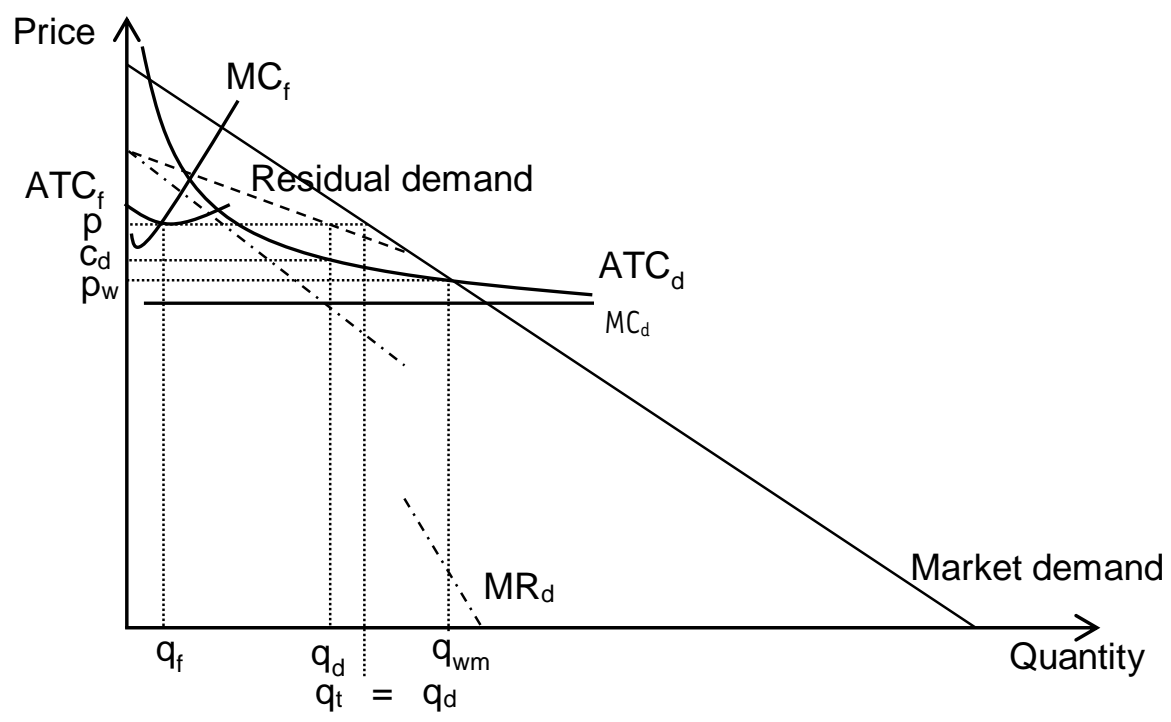

\section{FIGURE 2: Dominant firm with a competitive fringe}

\section{Source: Author's construction}

FIGURE 2 is an example where the government has incentivised a firm to invest in a large plant and so has a cost structure shown by $M C_{d}$ and $A T C_{d}$. Here the government might have used a combination of fixed and variable cost incentives. Had the firm not received these cost advantages it would have not have had the expected profits required to induce it to invest in a 
plant of this scale, and so may have built a plant similar in size and cost structures to those that make up the fringe.

Firms without these incentives will produce at a higher cost if the price at which the dominant firm supplies the market is sufficiently high. The aggregation of these fringe firms' cost structures is shown by $M C_{f}$ and $A T C_{f}$. The dominant firm, taking into account market demand and the demand that would be satisfied by fringe firms at high prices, identifies the residual demand over which it can act as a monopoly and sets its output accordingly. In the example in FIGURE 2 the marginal cost of the dominant firm intersects its marginal revenue function above the discontinuity, resulting in the dominant firm supplying $q_{d}$ and the fringe firms supplying $q_{f}$ in total.

In such an example it is even less clear how one ought to implement the CAC's suggestion. If the data is available it would be possible to apportion the fixed cost advantage over time and over output and add that advantage to the variable cost advantage to get the total value of special cost advantages received by the firm. This could then be added to the average total cost. The value of this exercise remains unclear, because the cost that results is unlikely to be the cost that would have resulted from a competitive market. Thus, such a process does not achieve the purpose of the CAC's suggestion of calculating some notional competitive norm of costs.

The central issue with the simple interpretation of the CAC's suggestion is that adding cost advantages to actual costs examines ex-post outcomes after constructing a counterfactual where ex-ante incentives are altered. This theme is discussed in detail in the literature in the context of how to enforce excessive pricing regulations in highly innovative markets. The conclusion here is that innovative firms need the incentive of large potential profits in the future should their innovation be successful in order for them to invest in the innovation. Enforcing excessive pricing regulations here needs to calculate the ex-ante risk and incorporate this into the ex-post pricing. Failure to do so would chill innovation. Furthermore, in highly innovative industries, this exercise is ordinarily impossible to undertake with any degree of confidence. Ultimately the suggestion is that excessive prices cases should be confined to industries which are not innovative (see, among others: Evans \& Padilla, 2005; Vickers, 2006; Fingleton, 2006).

One question then that does not get asked by the CAC's suggestion, but that possibly should, is: to what extent are the special cost advantages compensation for assuming some ex-ante risk? This question might be difficult or impossible to answer in the context of highly innovative industries; however, it might be easier to answer in the context of an industry where the method of business has not changed for a long period of time.

If one cannot use a simple interpretation of the CAC's suggestion and simply add the cost advantage to the actual cost of production, and the firm is not in an innovation industry, the question returns to how to calculate costs when trying to make a comparison between prices and economic value. Little clarity is added if one is tempted to alter the ex-post outcomes to adjust for the altered ex-ante incentives. Here the cost would be that which would have been incurred by the firm had it produced the profit-maximising output given a cost structure which does not

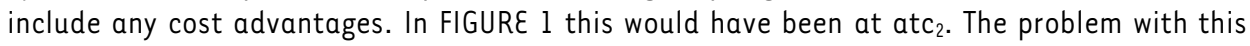
solution is that, although it takes into account how the changed incentives will alter what output the firm chooses to produce and hence where they lie on its cost curve, it is not a method to find the notional competitive norm but rather simply a different monopoly outcome. 
A third method of trying to apply the CAC's suggestion might be to use the cost that would result absent special cost advantages and if the market were competitive. This might provide a good approximation of the notional competitive norm; however, it involves calculating a cost based on altered cost curves and a different market structure. Modelling both these changes is difficult to do in practice. This is even more difficult in diminishing cost (natural monopoly) scenarios when a notional competitive outcome is not even theoretically possible.

Ultimately, then, there does not seem to be a practical method to implement the CAC's suggestion as it is currently understood. This conclusion would be different if the question were a firm-specific question about opportunity cost, because the analysis would simply need to quantify the value of the next best alternative use of those resources by the firm rather than attempting to model an entirely different universe of incentives, costs and market structures.

\section{WHAT IS THE SIZE OF THE SPECIAL COST ADVANTAGE}

In the discussion in the previous section it was neatly assumed that the value for the special cost advantage could be easily identified. This is not necessarily the case, because the price that the firm might pay in a contestable market for that input might be different to what firms are currently paying. Thus using the open market price for the competitive cost of the input would be inaccurate.

The reason why current market prices might be a poor proxy for what a firm might pay absent special cost advantages is because its bargaining position might be different. The costs of selling to a large customer are lower per unit than to small customers. Also the supplier's outside option of selling to the large customer might be below the average market price. In the case of this second point the value of the marginal sale should be taken as the cost rather than the market price. In a small market like South Africa this might mean that the export parity price is more often the valid counterfactual cost than the market price of that input. Furthermore, if the customer is very large, it might require investments in order to make that increase in exports possible.

These factors act to strengthen the large customer's position vis-à-vis the other smaller customers of the input producer, and ultimately imply that the price the large customer would receive would be lower than the market price. While this consideration is isolated to instances where the monopolist is a large customer of the input supplier, it might ring true with relative frequency in the types of industries that are prone to excessive prices cases. Overcompensating for these special cost advantages means that the monopoly would receive additional protection from excessive pricing laws (increase in type II enforcement errors).

Another measurement issue arises when the input market is supplied by a dominant firm and there is a vertical relationship between the dominant downstream firm and the dominant upstream firm. If the dominant downstream firm uses significant volumes of the dominant upstream firm's output, then the dominant upstream firm can price-discriminate to the remaining fringe customers. This price is unlikely to be indicative of a competitive market price were the downstream market to be competitive and have no relationship to the dominant upstream supplier. Measuring the competitive norm again becomes problematic. 


\section{ARE INDUSTRY ADVANTAGES SPECIAL COST ADVANTAGES}

The CAC's suggestion was specific to special cost advantages. This implies that other firms and indeed potential entrants are not given this advantage. This then necessitates a distinction to be made between whether the cost is applied broadly to an industry, or directed to a chosen firm. This distinction still needs to be made even if the industry structure is a monopoly.

Governments in developing countries specifically seek to advantage an industry in order to attain some developmental or national security goal. Such is the case where subsidies are placed on physical inputs to the production, skills development and indeed tax incentives for specific industries. The MIDP in South Africa allocates import credits to firms in order to incentivise them to produce motor vehicles in South Africa when they would otherwise have done so to a lesser extent if at all. This is an advantage given to any motor vehicle producer and, given the structure of the industry, there are many firms who receive this advantage. This then is not a special cost advantage, even though it would be a cost advantage.

This distinction becomes important when the cost advantage is allocated to an industry, and where the structure of that industry is a monopoly. Here the advantage might appear to be specific to a particular firm and hence a special cost advantage although the intention was to advantage the industry as a whole. In such cases it could be argued that the cost advantage is not special and hence should not be disregarded. It is thus important to establish whether or not the cost advantage would be available to entrants, or available to entrants at the time the cost advantage was made available to the industry.

The AMSA case provides a good example of the two different ways of conceptualising cost advantages in the case of a monopoly. At the time AMSA received iron ore at an especially low price of cost plus $3 \%$. AMSA received this special cost advantage from its historic position as being in the same company as the iron ore supplier (now Kumba). When Iscor was privatised and the iron ore and iron and steel works divisions were separated, the iron and steel works division received a contract for the supply of iron ore at cost plus $3 \%$. Using the CAC's suggestion, one could either advocate for the South Africa open market price or the export price instead of the cost plus $3 \%$ price.

The problems with adjusting AMSA's iron ore prices to either the South African price or the export price are numerous. Firstly, neither of these alternatives presents true opportunity costs of iron ore to AMSA. AMSA is by far the largest consumer of iron ore in South Africa, and so could not simply sell the iron ore it purchases from Kumba to the open market, certainly not at prevailing market prices. Secondly, the transport infrastructure could not support the increase in exports of iron ore that would occur if AMSA tried to export its iron ore instead of using it to produce steel. There may also be contractual obligations on AMSA to process the iron ore it receives at the preferential price rather than selling it to other customers of Kumba (this last point is speculative and only made for the purpose of illuminating an earlier point).

There are also problems at the underlying theoretical level. When Iscor was privatised and broken up it was not feasible to create many iron and steel companies. Indeed, this is still unlikely to be feasible. But, hypothetically, if the firm and market were large enough, Iscor could have been unbundled into a number of iron and steel companies. In this thought experiment, it is also likely that each of these iron and steel producers would have received its own contract with Kumba for iron ore to be supplied at cost plus $3 \%$. Thus the cost advantage would have been 
industry-wide rather than firm-specific, and thus not a special cost advantage but rather an industrial policy decision.

If the jurisprudence on this topic develops to identify all cost advantages to monopolies as special cost advantages, then this will severely restrict government's ability to develop downstream markets which are supplied by a monopolist. It is not entirely undermined, because even a monopolist which prices to the full extent of its market power will increase output and reduce price when its costs decrease. However, depending on price elasticity, it will be able to expropriate a portion of the cost advantage for itself. The more price-inelastic the demand, the greater the proportion of the cost advantage to the monopolist, and the smaller the price reduction.

\section{CONCLUSION}

The CAC's suggestion on special cost advantages stems from a conflation of opportunity cost and competitive norms. The two approaches can yield the same results, but this is not a foregone conclusion.

The result of simply adding the per unit value of the cost advantage to the firm's per unit costs does not result in the cost of production that would have resulted in a competitive market; it in fact results in a cost level which has no meaning or application whatsoever irrespective of market structure. It may be above the counterfactual monopoly cost if costs are increasing with output, and below the counterfactual monopoly cost if the costs are decreasing with output.

The issue with special cost advantages cannot be solved with as simple a solution as the CAC suggested. Rather it needs to be a carefully considered issue on a case-by-case basis that finds answers to questions as to why the cost advantage was offered in the first instance, whether or not other firms could hypothetically have received the benefit were they present in the market at that time, and what the opportunity cost of the subsidised factor or input is.

\section{LIST OF REFERENCES}

ArcelorMittal South Africa (AMSA). (2013). Company Background [www] AMSA. [0nline] Available: http://www.arcelormittalsa.com/Company/History.aspx. (Accessed 13 February 2013)

Competition Appeal Court of South Africa (CAC). (2009). Mittal Steel South Africa Ltd, MacSteel International BV and MacSteel Holdings Pty Ltd v Harmony Gold and Durban Roodepoort Deep, Case No: 70/CAC/Apr07.

Competition Tribunal of South Africa. (2007). Harmony Gold and Durban Roodepoort Deep v Mittal Steel South Africa Ltd, MacSteel International BV, Case No.: 13/CR/Feb04.

Evans, D. \& Padilla, J. (2005). Excessive Prices: Using Economics to define administrable legal rules, Journal of Competition Law and Economics, 1 (1), pp. 97-122.

Fingleton, J. (2006). De-monopolizing Ireland. In Ehlermann, C.D. \& Antanasiu, I. (eds.) European Competition Law Annual: 2003, What is an abuse of a dominant position? Hart Publishing.

Langbridge, S. \& MacKenzie, N. (2010). Excessive Pricing: Guidance from South Africa, European Competition Law Review, 31(9), pp. 354-361. 
Motta, M. \& De Streel, A. (2007). Excessive Pricing in Competition Law: Never Say Never? in The Pros and Cons of High Prices, Stockholm: Konkurrensverket - Swedish Competition Authority. Chapter 2, pp. 14-46.

Petersen, R., Maenetje, H. \& Le Roux, M. (2008). Submissions by Amici Curiae on the interpretation of section 8 (a) of the Competition Act, Competition Appeal Court ruling on the Harmony Mittal appeal, [Available from the registrar of the Competition Appeal Court upon request]

Vickers, J. (2007). Competition Law and Economics: A Mid-Atlantic Viewpoint, The Burrell Lecture of the Competition Law Association, given in London on 19 March 2007. 